\title{
Composição florística e chaves de identificação para as lianas da Estação Ecológica dos Caetetus, estado de São Paulo, Brasil ${ }^{1}$
}

\author{
Floristic composition and identification keys to the lianas \\ from Caetetus Ecological Station, São Paulo state, Brazil
}

Renata Giassi Udulutsch ${ }^{2}$, Vinicius Castro Souza ${ }^{3}$, Ricardo Ribeiro Rodrigues ${ }^{3}$ \& Pedro Dias ${ }^{2}$

\begin{abstract}
Resumo
Os estudos florísticos voltados às plantas mecanicamente dependentes (lianas e epífitas) permitiram vislumbrar a possível contribuição destes elementos para a riqueza e diversidade das florestas tropicais. No Brasil, o número de trabalhos enfocando especificamente o estudo florístico das lianas ainda é escasso. Nesse sentido, o presente estudo teve como objetivos caracterizar a composição florística de lianas e de seus mecanismos de ascensão na Estação Ecológica dos Caetetus, uma floresta estacional semidecidual do sudeste brasileiro, e apresentar chaves de identificação para as famílias e espécies de lianas deste fragmento florestal. Foram amostradas 74 espécies de 19 famílias, sendo as mais representativas Bignoniaceae (25 espécies), Sapindaceae (11), Apocynaceae (7), Malpighiaceae (7) e Fabaceae (6). Quanto aos mecanismos de ascensão, a forma preênsil foi a mais frequente, ocorrendo em 57\% das espécies. Baseando-se nos resultados obtidos e nos demais estudos florísticos que enfocaram essa forma de vida, foi possível verificar que, para as florestas estacionais semideciduais do sudeste brasileiro, a família com maior riqueza específica é Bignoniaceae, seguida por Sapindaceae e Malpighiacae, e o mecanismo de ascensão predominante para as espécies lenhosas é a forma preênsil.

Palavras-chave: floresta estacional semidecidual, mecanismos de ascensão, sudeste do Brasil.

Abstract

Floristic studies dedicated to non-self-supporting plants (lianas and epiphytes) made possible a better understanding of the contribution of these plants to the species richness and diversity of tropical forests. However, in Brazil, floristic studies on lianas are still rare. This study aimed at characterizing the floristic composition of lianas and their climbing mechanisms in a seasonal semideciduous forest in the Caetetus Ecological Station in southeastern Brazil, and providing identification keys to families and species of this forest fragment. We found 74 species belonging to 19 families, of which Bignoniaceae ( $25 \mathrm{spp}$.) is the most representative, followed by Sapindaceae (11 spp.), Apocynaceae (7 spp.), Malpighiaceae ( 7 spp.), and Fabaceae (6 spp.). As regards the attachment mechanisms, gripping was the most frequent (observed on 57\% of the species). Based on our results, as well as on previously published ones, we suggest that in seasonal semideciduous forests of southeastern Brazil, Bignoniaceae is the most species-rich family, followed by Sapindaceae and Malpighiaceae, and that gripping is the most frequent climbing mechanism of lianas.
\end{abstract}

Key words: seasonal semideciduous forest, climbing mechanisms, southeastern Brazil.

\section{Introdução}

As florestas tropicais são consideradas as mais ricas em espécies vegetais (Gentry \& Dodson 1987a; Steege et al. 2000), mas essa afirmação é geralmente baseada apenas no componente arbóreo
(Silva \& Leitão Filho 1982; Tabarelli \& Mantovani 1999; Feroz et al. 2006), pois ainda são pontuais os trabalhos que levam em conta outras formas de vida (e.g., Gentry \& Dodson 1987b; Putz \& Mooney 1991; Burns \& Dawson 2005).

\footnotetext{
'Parte da dissertação de mestrado da primeira autora. Autor para correspondência: udulutsch@gmail.com

${ }^{2}$ Universidade Federal do Oeste do Pará, Núcleo Universitário de Oriximiná, Lab. Sistemática Vegetal, Rodovia PA-254, 257, Santíssimo, 68270-000, Oriximiná, PA.

${ }^{3}$ Universidade de São Paulo, Escola Superior de Agricultura “Luiz de Queiroz”, Depto. Ciências Biológicas, Av. Pádua Dias 11, 13418-900, Piracicaba, SP.
} 
Com o início dos estudos florísticos voltados às plantas mecanicamente dependentes (e.g., epífitas e lianas), se começou a vislumbrar a possível contribuição destes elementos para a riqueza e diversidade das florestas tropicais (e.g., Menninger 1970; Putz 1984; Gentry \& Dodson 1987a,b; Gentry 1991; Hegarty \& Caballé 1991; Pérez-Salicrup et al. 2001b; Isnard \& Silk 2009). Alguns desses estudos têm sugerido que as lianas contribuem significativamente para a manutenção da diversidade e estrutura de uma floresta (Gentry 1991). Outros demonstraram que essa forma de vida pode ser responsável até mesmo por cerca de $34 \%$ do número de espécies de plantas vasculares (Gentry \& Dodson 1987a) e até 44\% das espécies lenhosas (Pérez-Salicrup et al. 2001b). Considerando-se não apenas o número de espécies, mas também a densidade de lianas, verifica-se valores extremamente elevados para este parâmetro em algumas florestas, as chamadas "florestas de lianas" (Balée \& Campbell 1990; Summerbell 1991), para as quais já foram registrados até 2.400 indivíduos por hectare (Pérez-Salicrup et al. 2001b).

Devido à maior diversidade e abundância de lianas ocorrerem em florestas tropicais, onde são elementos característicos (Richards 1952; Gentry 1991), essa forma de vida constitui um importante componente florístico, estrutural e funcional nessas florestas (Gentry 1991; Isnard \& Silk 2009). Consequentemente, fatores naturais, incluindo os físico-climáticos, e antrópicos, como a abertura de clareiras, podem influenciar diretamente em sua diversidade florística (Leitão Filho 1995; Morellato \& Leitão Filho 1998; Udulutsch et al. 2004). Dessa forma, determinar os mecanismos que mantêm a diversidade para cada forma de vida é essencial para compreendermos como se dá a manutenção local da própria diversidade de espécies (Schnitzer \& Carson 2001; Schnitzer \& Bongers 2002) e até mesmo como as diversas formas de vida estão relacionadas (Hegarty 1991; Muoghalu \& Okeesan 2005).

Nesse sentido, a relação liana-forófito poderia ser vista, em um primeiro momento, como a citada por Steentoft (1988), na qual existe uma relação comensal, em que uma espécie se beneficia do suporte proporcionado por outra (forófito), que não é prejudicada por estruturas haustoriais. No entanto, vários estudos demonstraram que as lianas competem com as árvores por luz, água e nutrientes, o que pode alterar as taxas de crescimento, mortalidade e fecundidade dos forófitos (Lowe \& Walker 1977; Putz \& Chai 1987; Clark \& Clark 1990). Talvez assim as lianas atuem como uma importante força seletiva na evolução do componente arbóreo em matas tropicais (Putz 1984). Um outro fator que recentemente passou a ser considerado é o papel das lianas em alguns processos ecológicos, tais como a transpiração total e o sequestro de carbono, que estão diretamente ligados ao equilíbrio do ecossistema. Considerando a alta densidade de lianas nas florestas tropicais e que a maioria destas plantas se mantêm verdes mesmo durante a estação seca (período em que muitas árvores estão decíduas), há grande contribuição para a transpiração dessas florestas, particularmente durante o período mais seco (Schnitzer \& Bongers 2002). Por outro lado, uma intensa ocupação por lianas, após algum distúrbio natural ou antrópico, inibe a regeneração de árvores, reduzindo a quantidade de carbono sequestrado em biomassa vegetal (Schnitzer \& Bongers 2002). Portanto, as lianas também representam um papel crucial na regeneração florestal, manutenção da diversidade e, consequentemente, na dinâmica florestal.

Apesar de sua importância nas florestas tropicais, na maioria das vezes as lianas são coletadas apenas de forma (in)oportuna, não sendo abordadas como o principal objetivo de estudos florísticos e fitossociológicos (Gentry 1991). Essa relativa escassez de trabalhos sobre lianas deve estar associada, principalmente, às dificuldades práticas para a coleta de amostras no dossel (Putz 1984), além da própria dificuldade associada ao estudo de uma forma de vida que apresenta um modelo de crescimento irregular e reprodução vegetativa intensa (Schnitzer \& Bongers 2002), muitas vezes impossibilitando a delimitação do próprio indivíduo.

No Brasil, o número de trabalhos enfocando especificamente o estudo florístico das lianas, apesar de ter aumentado nos últimos anos, ainda é tímido. Esses trabalhos foram realizados, em sua maioria, em florestas estacionais semideciduais (Morellato \& Leitão Filho 1998; Hora \& Soares 2002; Udulutsch et al. 2004; Rezende \& Ranga 2005; Tibiriçá et al. 2006; Rezende et al. 2007; Durigon et al. 2009) e em florestas ombrófilas, tanto no domínio amazônico (Gentry 1991; Oliveira et al. 2008) quanto no domínio atlântico (Lima et al. 1997; Barros et al. 2009).

Trabalhos que trazem chaves de identificação para grupos lianescentes são ainda mais escassos, principalmente se considerarmos chaves baseadas exclusivamente em caracteres vegetativos. Dentre os poucos estudos, Gentry (1996) elaborou um guia de campo contendo chaves de identificação para grupos de famílias e grupos de gêneros ocorrentes 
no noroeste da América do Sul, que são, em sua maioria, baseadas em dados vegetativos. A única chave para famílias de lianas, baseada exclusivamente em caracteres vegetativos, foi feita por Vaz \& Vieira (1994) para uma área de floresta ombrófila.

Nesse sentido, este trabalho teve como principal objetivo caracterizar a composição florística de lianas em uma floresta estacional semidecidual do estado de São Paulo, ressaltando suas diferenças biomecânicas. Adicionalmente, também é apresentada a variação na composição florística desta forma de vida para outras florestas tropicais, em especial para as florestas estacionais semideciduais do sudeste brasileiro, e chaves de identificação baseadas exclusivamente em caracteres vegetativos.

\section{Material e Métodos}

\section{Área de estudo}

A Estação Ecológica dos Caetetus (EEC) possui uma área contínua de 2.178,84 ha situada nos municípios de Gália e Alvinlândia, no planalto ocidental do estado de São Paulo, entre as coordenadas geográficas $22^{\circ} 41^{\prime}$ a $22^{\circ} 46^{\prime} \mathrm{S} \mathrm{e} 49^{\circ} 10^{\prime}$ a $49^{\circ} 16^{\prime} \mathrm{W}$, e está incluída na bacia hidrográfica do Médio Paranapanema. Predominam nas áreas mais elevadas da EEC (altitude média de $650 \mathrm{~m}$ ) o latossolo de textura média álico, enquanto nas partes mais baixas (altitude média de $550 \mathrm{~m}$ ) o podzólico vermelho - amarelo profundo de textura arenosa/média (Mattos et al. 1996). O clima local, segundo a proposta de classificação de Köppen (1948), é Cwa (mesotérmico de inverno seco).

De acordo com a classificação de Veloso \& Góes-Filho (1982), a EEC caracteriza-se como um grande remanescente de floresta estacional semidecidual. Essa formação florestal, que revestia originalmente a Depressão Periférica, a Cuesta Basáltica e parte do Planalto Ocidental do interior paulista, representa atualmente a formação florestal mais ameaçada do Estado, face à sua fragmentação como consequência de alterações antrópicas, dado que quase toda sua área de ocupação original é agriculturável (Mattos et al. 1996).

\section{Amostragem florística}

As expedições de coleta foram realizadas mensalmente, no período de março de 2002 a dezembro de 2003.

O levantamento florístico foi feito nas parcelas alocadas pelo projeto "Diversidade, dinâmica e conservação em florestas do estado de
São Paulo: 40 ha de parcelas permanentes" (vinculado ao Programa Biota/FAPESP). Das 256 parcelas contíguas de $20 \times 20 \mathrm{~m}$ alocadas pelo referido projeto, foram sorteadas 50 , perfazendo uma área total de $2 \mathrm{ha}$. Foram amostradas todas as lianas (trepadeiras lenhosas), férteis ou não, ocorrentes nas parcelas sorteadas, sendo consideradas como integrantes de uma determinada parcela aquelas que possuíam ao menos ramos com folhas dentro da parcela, independentemente da base estar ou não ligada ao solo dentro da área delimitada.

Por outro lado, além dos indivíduos de dentro das parcelas, também foram coletados aqueles encontrados ao longo das trilhas e na borda do remanescente florestal. Essas coletas efetuadas fora das parcelas (trilhas e borda) incluíram todos os indivíduos encontrados em estágio reprodutivo.

As coletas foram realizadas utilizando-se tesoura de poda alta e, na maioria das vezes, técnicas de escalada. O material coletado foi herborizado e as exsicatas depositadas no Herbário ESA (Escola Superior de Agricultura "Luiz de Queiroz", Universidade de São Paulo). As identificações foram feitas utilizando-se bibliografia especializada e, quando necessário, com o auxílio de especialistas e/ ou por comparação com exsicatas disponíveis nos herbários ESA, HRCB, SP, SPF e UEC.

As categorias de lianas empregadas neste estudo (modificadas de Putz \& Windsor 1987; Veloso 1991; Lima et al. 1997) foram: preênseis (com gavinhas ou ganchos), volúveis (com caules que envolvem o forófito de forma helicoidal) e escandentes (com caules longos e divaricados, que se apóiam em outras plantas e, muitas vezes, apresentam estruturas especializadas que auxiliam no apoio ao forófito, como espinhos).

Foi elaborada uma chave de identificação para as famílias de lianas ocorrentes na EEC e chaves para as espécies de cada família, todas dicotômicas e baseadas exclusivamente em caracteres vegetativos. As circunscrições das famílias utilizadas neste trabalho estão de acordo com o APG III (2009).

\section{Resultados}

Foram amostradas 74 espécies de lianas, pertencentes a 52 gêneros e 19 famílias (Tab. 1).

As famílias com maior riqueza específica foram: Bignoniaceae, com 25 espécies (34\%); Sapindaceae, com 11 espécies (15\%); Apocynaceae e Malpighiaceae, com sete espécies (9\%) cada; e Fabaceae, com seis espécies (8\%). Essas cinco famílias representam $75 \%$ das espécies encontradas neste levantamento. 
Tabela 1 - Lianas da Estação Ecológica dos Caetetus (SP, Brasil), material testemunho (coletor: R.G. Udulutsch) e mecanismos de ascensão.

Table 1 - Lianas from the Caetetus Ecological Station (SP, Brazil), voucher information (collector: R.G. Udulutsch), and climbing mechanisms.

\begin{tabular}{|c|c|c|c|c|}
\hline \multirow[t]{2}{*}{ Família } & \multirow[t]{2}{*}{ Espécie } & \multicolumn{2}{|c|}{ \# de coletor } & \multirow{2}{*}{$\begin{array}{l}\text { Mecanismo de } \\
\text { ascensão }\end{array}$} \\
\hline & & parcelas & $\begin{array}{r}\text { trilhas } \\
\text { e borda }\end{array}$ & \\
\hline Acanthaceae & Mendoncia velloziana Mart. & & 1658 & volúvel \\
\hline Amaranthaceae & Hebanthe paniculata Mart. & 1628 & 2390 & volúvel \\
\hline \multirow[t]{7}{*}{ Apocynaceae } & Condylocarpon isthmicum (Vell.) A. DC. & 1462 & 498 & volúvel \\
\hline & Forsteronia australis Müll. Arg. & 1611 & & volúvel \\
\hline & Forsteronia pilosa (Vell.) Müll. Arg. & 737 & 749 & volúvel \\
\hline & Forsteronia pubescens DC. & 1599 & & volúvel \\
\hline & Prestonia coalita (Vell.) Woodson & 1590 & 497 & volúvel \\
\hline & Prestonia tomentosa $\mathrm{R}$. Br. & & 538 & volúvel \\
\hline & Temnadenia violacea (Vell.) Miers & 1464 & 1466 & volúvel \\
\hline \multirow[t]{22}{*}{ Bignoniaceae } & Adenocalymma bracteatum (Cham.) DC. & & 1206 & preênsil \\
\hline & Adenocalymma marginatum (Cham.) DC. & 2490 & 528 & preênsil \\
\hline & Adenocalymma paulistarum Bureau ex K. Schum. & 1193 & 1207 & preênsil \\
\hline & Amphilophium paniculatum (L.) Kunth & 517 & 748 & preênsil \\
\hline & Anemopaegma chamberlaynii (Sims) Bureau \& K. Schum. & 532 & 1196 & preênsil \\
\hline & Arrabidaea chica (Humb. \& Bonpl.) B. Verl. & & 1205 & preênsil \\
\hline & Arrabidaea conjugata (Vell.) Mart. & 516 & 2375 & preênsil \\
\hline & Arrabidaea florida DC. & 1657 & 745 & preênsil \\
\hline & Arrabidaea pulchella Bureau & & 1204 & preênsil \\
\hline & Arrabidaea pulchra (Cham.) Sandwith & 2477 & 2376 & preênsil \\
\hline & Arrabidaea samydoides (Cham.) Sandwith & & 495 & preênsil \\
\hline & Arrabidaea triplinervia (Mart. ex DC.) Baill. ex Bureau & & 503 & preênsil \\
\hline & Clytostoma sciuripabulum Bureau \& K. Schum. & 1608 & 1644 & preênsil \\
\hline & Cuspidaria convoluta (Vell.) A.H. Gentry & & 534 & preênsil \\
\hline & Distictella elongata (Vahl) Urb. & & 1210 & preênsil \\
\hline & Fridericia speciosa Mart. & & 1209 & preênsil \\
\hline & Glaziovia bauhinioides Bureau ex Baill. & 1634 & & preênsil \\
\hline & Lundia obliqua Sonder & 1610 & 493 & preênsil \\
\hline & Macfadyena mollis (Sond.) Seem. & 1478 & & preênsil \\
\hline & Macfadyena unguis-cati (L.) A.H. Gentry & 1625 & 490 & preênsil \\
\hline & Mansoa difficilis (Cham.) Bureau \& K. Schum. & 2506 & 519 & preênsil \\
\hline & Pithecoctenium crucigerum (L.) A.H. Gentry & 2511 & & preênsil \\
\hline \multirow[t]{3}{*}{ Bignoniaceae } & Pyrostegia venusta (Ker Gawl.) Miers & 2515 & 2497 & preênsil \\
\hline & Stizophyllum perforatum (Cham.) Miers & 1613 & 1194 & preênsil \\
\hline & Tynanthus micranthus Corr. Méllo ex K. Schum. & 1619 & & preênsil \\
\hline Cactaceae & Pereskia aculeata Mill. & 507 & 518 & escandente \\
\hline \multirow[t]{2}{*}{ Celastraceae } & Anthodon decussatum Ruiz \& Pav. & 1623 & & preênsil \\
\hline & Hippocratea volubilis L. & 2525 & & preênsil \\
\hline \multirow[t]{2}{*}{ Dilleniaceae } & Davilla rugosa Poir. & 1486 & 1581 & volúvel \\
\hline & Doliocarpus dentatus (Aubl.) Standl. & & 520 & escandente \\
\hline \multirow[t]{2}{*}{ Fabaceae } & Acacia mollissima Willd. & & 500 & escandente \\
\hline & Acacia plumosa Lowe & 1490 & 869 & escandente \\
\hline
\end{tabular}




\begin{tabular}{|c|c|c|c|c|}
\hline \multirow[t]{2}{*}{ Família } & \multirow[t]{2}{*}{ Espécie } & \multicolumn{2}{|c|}{ \# de coletor } & \multirow{2}{*}{$\begin{array}{l}\text { Mecanismo de } \\
\text { ascensão }\end{array}$} \\
\hline & & parcelas & $\begin{array}{r}\text { trilhas } \\
\text { e borda }\end{array}$ & \\
\hline & Acacia polyphylla DC. & & 820 & escandente \\
\hline & Bauhinia microstachya (Raddi) J.F. Macbr. & 1489 & & preênsil \\
\hline & Dalbergia frutescens (Vell.) Britton & 1616 & 502 & preênsil \\
\hline & Dioclea cf. virgata (Rich.) Amshoff & & 531 & volúvel \\
\hline \multirow[t]{7}{*}{ Malpighiaceae } & Banisteriopsis muricata (Cav.) Cuatrec. & 511 & 527 & volúvel \\
\hline & Banisteriopsis oxyclada (A. Juss.) B. Gates & & 494 & volúvel \\
\hline & Dicella bracteosa (A. Juss.) Griseb. & 1645 & 526 & volúvel \\
\hline & Heteropterys sp. & 1632 & & volúvel \\
\hline & Mascagnia cordifolia (A. Juss.) Griseb. & 1491 & & volúvel \\
\hline & Tetrapterys multiglandulosa A. Juss. & & 499 & volúvel \\
\hline & Tetrapterys phlomoides (Sprengel) Nied. & & 501 & volúvel \\
\hline Malvaceae & Byttneria catalpifolia Jacq. & 1635 & 1655 & volúvel \\
\hline \multirow[t]{2}{*}{ Nyctaginaceae } & Bougainvillea glabra Choisy & 506 & & escandente \\
\hline & Pisonia aculeata $\mathrm{L}$. & 2485 & 2380 & escandente \\
\hline Phytolaccaceae & Seguieria americana $\mathrm{L}$. & 1495 & & escandente \\
\hline Rhamnaceae & Gouania acalyphoides Reissek & 1641 & 742 & preênsil \\
\hline \multirow[t]{11}{*}{ Sapindaceae } & Cardiospermum grandiflorum $\mathrm{Sw}$. & & 831 & preênsil \\
\hline & Paullinia rhomboidea Radlk. & & 1652 & preênsil \\
\hline & Serjania caracasana (Jacq.) Willd. & 1502 & 1008 & preênsil \\
\hline & Serjania fuscifolia Radlk. & 1505 & 2392 & preênsil \\
\hline & Serjania glabrata Kunth & 2549 & & preênsil \\
\hline & Serjania laruotteana Cambess. & 1618 & 2487 & preênsil \\
\hline & Serjania meridionalis Cambess. & 1643 & 525 & preênsil \\
\hline & Serjania multiflora Cambess. & & 2391 & preênsil \\
\hline & Serjania pinnatifolia Radlk. & & 2393 & preênsil \\
\hline & Thinouia ventricosa Radlk. & 1597 & & preênsil \\
\hline & Urvillea laevis Radlk. & 1638 & & preênsil \\
\hline Solanaceae & Lycianthes australe (Morton) A.T. Hunz. \& Barboza & 1498 & 513 & volúvel \\
\hline Solanaceae & Solanum hirtellum (Spreng.) Hassl. & 756 & 1593 & escandente \\
\hline Trigoniaceae & Trigonia nivea Cambess. & & 747 & volúvel \\
\hline Ulmaceae & Celtis iguanae (Jacq.) Sarg. & & 1592 & escandente \\
\hline Verbenaceae & Petrea volubilis $\mathrm{L}$. & & 2381 & volúvel \\
\hline Vitaceae & Cissus verticillata (L.) Nicolson \& C.E. Jarvis & 1497 & & preênsil \\
\hline
\end{tabular}

Do total de espécies amostradas, foram encontradas 50 (15 famílias) nas parcelas e 57 (16 famílias) nas coletas aleatórias (trilhas e borda), sendo que 33 espécies foram comuns para as duas situações (parcela e trilhas/borda). Dentre as espécies ocorrentes nas parcelas, cinco foram encontradas exclusivamente em bordas de clareiras, sendo elas: Adenocalymma marginatum (Cham.) DC. e Arrabidaea conjugata (Vell.) Mart. (Bignoniaceae), Acacia plumosa Lowe (Fabaceae), Lycianthes australe (Morton) A.T. Hunz. \& Barboza e Solanum hirtellum (Spreng.) Hassl. (Solanaceae).

Por outro lado, também foram encontradas espécies exclusivas das trilhas e borda do fragmento, sendo elas: Prestonia tomentosa R. Br. (Apocynaceae), Arrabidaea triplinervia (Mart. ex DC.) Baill. ex Bureau 
e Distictella elongata (Vahl) Urb. (Bignoniaceae), Doliocarpus dentatus (Aubl.) Standl. (Dilleniaceae), Tetrapterys phlomoides (Sprengel) Nied. (Malpighiaceae), Trigonia nivea Cambess. (Trigoniaceae) e Celtis iguanae (Jacq.) Sarg. (Ulmaceae).

Bignoniaceae, Malpighiaceae e Sapindaceae foram as famílias que apresentaram maior número de gêneros (16 para a primeira e cinco para as duas últimas). Dentre tais gêneros, Arrabidaea DC. e Serjania Mill. destacaram-se com o maior número de espécies (sete em cada) e pertencem às duas famílias com maior riqueza específica (Bignoniaceae e Sapindaceae). Adicionalmente, a maioria dos gêneros $(83 \%)$ é representada por uma única espécie.

Quanto aos mecanismos de ascensão (Tab. 1), a forma preênsil foi a mais comum, ocorrendo em $57 \%$ das espécies amostradas (42 espécies) e os órgãos que caracterizam essa forma de ascensão nas lianas da EEC foram as gavinhas (39 espécies) e os ganchos (três espécies). Bignoniaceae, Fabaceae, Rhamnaceae e Sapindaceae possuem representantes com gavinhas, as quais são de origem foliar em Bignoniaceae e caulinar nas demais. Ganchos estiveram presentes apenas em Celastraceae e Fabaceae. Dentre as famílias com representantes preênseis, a única que não apresentou exclusividade para essa forma de ascensão foi Fabaceae, que inclui também espécies escandentes (Acacia spp.) e uma volúvel (Dioclea cf. virgata (Rich.) Amshoff).

Todas as espécies das famílias Acanthaceae, Amaranthaceae, Apocynaceae, Malpighiaceae, Malvaceae e Verbenaceae apresentaram a forma volúvel como mecanismo de ascensão, totalizando 22 espécies (29\%).

As lianas escandentes, por outro lado, estão representadas em menor número (10 espécies, 14\%)e a maioria das espécies desta categoria apresentou espinhos como estrutura auxiliar na fixação ao forófito, sendo a única exceção Solanum hirtellum. As espécies de Acacia apresentaram outra adaptação que auxilia na fixação: a porção apical dos ramos encurvada. Nas Cactaceae, Nyctaginaceae, Phytolaccaceae e Ulmaceae a forma escandente foi exclusiva.

\section{Discussão}

O número de espécies encontrado neste fragmento florestal revela a importante participação das lianas na diversidade das florestas estacionais semideciduais do estado de São Paulo, corroborando os resultados encontrados em outros levantamentos realizados no mesmo tipo de formação florestal (e.g., Morellato \& Leitão Filho 1998; Durigon et al. 2009).
Levantamentos florísticos voltados exclusivamente à caracterização das lianas em florestas tropicais também têm reforçado a importância deste componente na riqueza das comunidades (Tab. 2). De um modo geral, as florestas estacionais apresentam um elevado número de espécies por hectare quando comparadas com as florestas ombrófilas. Esse resultado é reforçado principalmente se compararmos os estudos que utilizaram os mesmos critérios de inclusão e esforço amostral (Udulutsch 2004; Zhu 2008).

No Brasil, apenas o estudo de Udulutsch (2004), realizado em floresta ombrófila, utilizou o mesmo critério de inclusão e esforço amostral descritos no presente trabalho. Nesse estudo foi registrada a ocorrência de 37 espécies de lianas em 2 ha (contra 50 espécies listadas no presente estudo para uma floresta estacional).

Fora do Brasil, pode ser citado como exemplo o trabalho de Zhu (2008), o qual também utilizou os mesmos métodos de amostragem em uma floresta ombrófila e em uma floresta estacional na mesma localidade (Yunnan, China). Nesse estudo, foram amostradas 32 espécies de lianas na floresta ombrófila e 62 espécies na floresta estacional.

Apesar desses estudos pontuais, a maioria dos dados disponíveis na literatura sobre as florestas ombrófilas não permite uma comparação precisa com as florestas estacionais, pois o esforço amostral relacionado ao tempo e à área de amostragem são muito distintos. Por exemplo, os trabalhos de Lima et al. (1997) e Barros et al. (2009) foram realizados em áreas de 7.200 e 2.400 ha, em períodos de 3 e 10 anos, respectivamente, enquanto a maioria dos estudos realizados em florestas estacionais foram feitos em áreas de 1 a 2 ha por períodos de um a dois anos.

Para a área estudada, as cinco famílias com maior riqueza específica (Bignoniaceae, Sapindaceae, Apocynaceae, Malpighiaceae e Fabaceae) corresponderam a $75 \%$ das espécies encontradas, evidenciando que existe um pequeno número de famílias que apresentam um número elevado de espécies, corroborando tanto a afirmação de Gentry (1991), de que nas florestas neotropicais $85 \%$ das espécies de lianas estão distribuídas em 26 famílias, quanto os resultados encontrados nos demais estudos realizados em florestas estacionais semideciduais do estado de São Paulo (e.g., Morellato \& Leitão Filho 1998; Rezende et al. 2007). As famílias citadas acima estão entre as 10 mais 
Tabela 2 - Riqueza de espécies de lianas e famílias mais ricas em florestas tropicais.

Table 2 - Species richness of lianas and most species-rich families in tropical forests.

\begin{tabular}{|c|c|c|c|c|c|c|c|}
\hline Continente & $\begin{array}{l}\text { Tipo de } \\
\text { floresta }\end{array}$ & Localidade & $\begin{array}{l}\text { Área } \\
\text { (ha) }\end{array}$ & $\begin{array}{c}\text { Critério } \\
\text { de inclusão }\end{array}$ & \# de spp. ${ }^{a}$ & Famílias mais ricas & Referência \\
\hline \multirow[t]{11}{*}{ América do Sul } & Estacional & Bolívia, Santa Cruz & 1,08 & $\mathrm{DAP} \geq 2 \mathrm{~cm}$ & 52 & $\begin{array}{l}\text { Malpighiaceae } \\
\text { Fabaceae } \\
\text { Bignoniaceae }\end{array}$ & Pérez-Salicrup et al. (2001b) \\
\hline & Estacional & Brasil, SP, Campinas & $1-2^{b}$ & todas & 96 & $\begin{array}{l}\text { Bignoniaceae } \\
\text { Malpighiaceae } \\
\text { Asteraceae/Sapindaceae }\end{array}$ & Morellato \& Leitão Filho (1998) \\
\hline & Estacional & Brasil, SP, Gália & 2 & todas & 50 & $\begin{array}{l}\text { Bignoniaceae } \\
\text { Sapindaceae } \\
\text { Apocynaceae/Malpighiaceae }\end{array}$ & Presente estudo \\
\hline & Estacional & $\begin{array}{l}\text { Brasil, SP, } \\
\text { Paulo de Faria }\end{array}$ & 1 & $\mathrm{DAP} \geq 1 \mathrm{~cm}$ & 45 & $\begin{array}{l}\text { Bignoniaceae } \\
\text { Sapindaceae } \\
\text { Malpighiaceae }\end{array}$ & Rezende et al. (2007) \\
\hline & Estacional & Brasil, SP, Rio Claro & $1-2^{b}$ & todas & 93 & $\begin{array}{l}\text { Bignoniaceae } \\
\text { Asteraceae } \\
\text { Sapindaceae }\end{array}$ & Udulutsch et al. (2004) \\
\hline & Estacional & $\begin{array}{l}\text { Brasil, SP, Santa } \\
\text { Rita do Passa Quatro }\end{array}$ & $1-2^{b}$ & todas & 92 & $\begin{array}{l}\text { Bignoniaceae } \\
\text { Malpighiaceae } \\
\text { Sapindaceae }\end{array}$ & Tibiriçá et al. (2006) \\
\hline & Estacional & Brasil, SP, São Carlos & 0,75 & $\mathrm{DAP} \geq 2,5 \mathrm{~cm}$ & 45 & $\begin{array}{l}\text { Bignoniaceae } \\
\text { Malpighiaceae/Sapindaceae } \\
\text { Apocynaceae }\end{array}$ & Hora \& Soares (2002) \\
\hline & Estacional & $\begin{array}{l}\text { Brasil, SP, } \\
\text { São José do Rio Preto }\end{array}$ & $1-2^{b}$ & todas & 67 & $\begin{array}{l}\text { Bignoniaceae } \\
\text { Sapindaceae } \\
\text { Fabaceae/Malpighiaceae }\end{array}$ & Rezende \& Ranga (2005) \\
\hline & $\begin{array}{l}\text { Ombrófila } \\
\text { (domínio amazônico) }\end{array}$ & Brasil, AM, Manaus & 3 & $\mathrm{DAP} \geq 10 \mathrm{~cm}$ & 22 & $\begin{array}{l}\text { Fabaceae } \\
\text { Menispermaceae } \\
\text { Polygalaceae }\end{array}$ & Oliveira et al. (2008) \\
\hline & $\begin{array}{l}\text { Ombrófila } \\
\text { (domínio amazônico) }\end{array}$ & $\begin{array}{l}\text { Brasil, PA, Belém } \\
\text { (Reserva do Mocambo) }\end{array}$ & 0,1 & $\mathrm{DAP} e+2,5 \mathrm{~cm}$ & 25 & $\begin{array}{l}\text { Bignoniaceae } \\
\text { Fabaceae } \\
\text { Connaraceae }\end{array}$ & Gentry (1991) \\
\hline & $\begin{array}{l}\text { Ombrófila } \\
\text { (domínio amazônico) }\end{array}$ & Peru, Yanamono & 0,1 & $\mathrm{DAP} \geq 2,5 \mathrm{~cm}$ & 44 & $\begin{array}{l}\text { Fabaceae } \\
\text { Bignoniaceae } \\
\text { Malpighiaceae }\end{array}$ & Gentry (1991) \\
\hline
\end{tabular}




\begin{tabular}{|c|c|c|c|c|c|c|c|}
\hline Continente & $\begin{array}{l}\text { Tipo de } \\
\text { floresta }\end{array}$ & Localidade & $\begin{array}{c}\text { Área } \\
\text { (ha) }\end{array}$ & $\begin{array}{c}\text { Critério } \\
\text { de inclusão }\end{array}$ & \# de spp. ${ }^{a}$ & Famílias mais ricas & Referência \\
\hline & $\begin{array}{l}\text { Ombrófila } \\
\text { (domínio atlântico) }\end{array}$ & $\begin{array}{l}\text { Brasil, SP, Sete Barras, } \\
\text { Parque Estadual } \\
\text { Carlos Botelho }\end{array}$ & 2 & todas & 37 & $\begin{array}{l}\text { Fabaceae } \\
\text { Apocynaceae } \\
\text { Celastraceae }\end{array}$ & Udulutsch (2004) \\
\hline & $\begin{array}{l}\text { Ombrófila } \\
\text { (domínio atlântico) }\end{array}$ & $\begin{array}{l}\text { Brasil, RJ, } \\
\text { Reserva Ecológica } \\
\text { de Macaé de Cima }\end{array}$ & 7.200 & $\mathrm{DAP} \geq 2,5 \mathrm{~cm}$ & $87^{c}$ & $\begin{array}{l}\text { Asteraceae } \\
\text { Malpighiaceae } \\
\text { Fabaceae }\end{array}$ & Lima et al. (1997) \\
\hline & $\begin{array}{l}\text { Ombrófila } \\
\text { (domínio atlântico) }\end{array}$ & $\begin{array}{l}\text { Brasil, RJ, } \\
\text { Parque Estadual } \\
\text { Serra da Tiririca }\end{array}$ & 2.400 & todas & 125 & $\begin{array}{l}\text { Sapindaceae } \\
\text { Bignoniaceae } \\
\text { Fabaceae }\end{array}$ & Barros et al. (2009) \\
\hline \multirow[t]{2}{*}{ América Central } & Ombrófila & Costa Rica, Monteverde & 0,4 & $\mathrm{DAP} \geq 2,5 \mathrm{~cm}$ & 19 & $\begin{array}{l}\text { Asteraceae } \\
\text { Sapindaceae } \\
\text { Vitaceae }\end{array}$ & Krings (2000) \\
\hline & Estacional & $\begin{array}{l}\text { Panamá, } \\
\text { Barro Colorado }\end{array}$ & 1 & todas & 65 & $\begin{array}{l}\text { Bignoniaceae } \\
\text { Sapindaceae } \\
\text { Celastraceae/Fabaceae }\end{array}$ & Putz (1984), Putz \& Windsor (1987) \\
\hline América do Norte & Ombrófila & México, Lacandon & 4 & $\mathrm{DAP} \geq 1 \mathrm{~cm}$ & 90 & $\begin{array}{l}\text { Bignoniaceae } \\
\text { Malpighiaceae } \\
\text { Fabaceae }\end{array}$ & $\begin{array}{l}\text { Ibarra-Manríquez \& Martínez- } \\
\text { Ramos (2002) }\end{array}$ \\
\hline \multirow[t]{4}{*}{ Ásia } & Estacional & $\begin{array}{l}\text { China, Yunnan, } \\
\text { Xishuangbanna }\end{array}$ & 0,5 & $\mathrm{DAP} \geq 1 \mathrm{~cm}$ & 62 & $\begin{array}{l}\text { Annonaceae } \\
\text { Fabaceae } \\
\text { Vitaceae }\end{array}$ & Zhu (2008) \\
\hline & Ombrófila & $\begin{array}{l}\text { China, Yunnan, } \\
\text { Xishuangbanna }\end{array}$ & 0,5 & $\mathrm{DAP} \geq 1 \mathrm{~cm}$ & 32 & $\begin{array}{l}\text { Fabaceae } \\
\text { Celastraceae } \\
\text { Annonaceae }\end{array}$ & Zhu (2008) \\
\hline & Ombrófila & $\begin{array}{l}\text { Índia, Varagalaiar, } \\
\text { Western Ghats }\end{array}$ & 30 & $\mathrm{DAP} \geq 1 \mathrm{~cm}$ & 75 & $\begin{array}{l}\text { Fabaceae } \\
\text { Apocynaceae } \\
\text { Vitaceae }\end{array}$ & $\begin{array}{l}\text { Muthuramkumar \& Parthasarathy } \\
(2000)\end{array}$ \\
\hline & Ombrófila & $\begin{array}{l}\text { Malásia, Sarawak, } \\
\text { Lambir National Park }\end{array}$ & 1,4 & $\mathrm{DAP} \geq 1 \mathrm{~cm}$ & 79 & $\begin{array}{l}\text { Fabaceae } \\
\text { Icacinaceae } \\
\text { Annonaceae }\end{array}$ & Putz \& Chai (1987) \\
\hline \multirow[t]{2}{*}{ África } & Estacional & Nigéria, Ile-Ife & 0,25 & todas & 35 & $\begin{array}{l}\text { Ampelidaceae } \\
\text { Apocynaceae } \\
\text { Connaraceae }\end{array}$ & Muoghalu \& Okeesan (2005) \\
\hline & Estacional & Uganda, Budongo & 1 & $\mathrm{DAP} \geq 1 \mathrm{~cm}$ & 62 & $\begin{array}{l}\text { Celastraceae } \\
\text { Apocynaceae } \\
\text { Dichapetalaceae }\end{array}$ & Eilu (2000) \\
\hline
\end{tabular}


ricas em espécies de lianas do Novo Mundo (Gentry 1991), embora a ordem de riqueza não seja exatamente a mesma: Fabaceae ocupa a $3^{\mathrm{a}}$ posição, Bignoniaceae a $6^{\mathrm{a}}$, Sapindaceae a $7^{\mathrm{a}}$, Malpighiaceae a $8^{\mathrm{a}}$ e Apocynaceae a $10^{\mathrm{a}}$ posição. Entretanto, é importante ressaltar que as comparações com os dados apresentados por Gentry (1991) devem ser feitas com ressalvas, dado que além das lianas, o autor incluiu trepadeiras herbáceas e hemiepífitas. Para exemplificar, os primeiro e segundo lugares são ocupados, respectivamente, por Apocynaceae (apenas as Asclepiadoideae) e Convolvulaceae, duas famílias compostas quase que exclusivamente por trepadeiras herbáceas, e o quinto lugar é ocupado por Araceae, uma família com a maioria dos representantes hemiepífita. Portanto, se fossem consideradas apenas as famílias representadas predominantemente por lianas, as mais representativas seriam: Fabaceae, Asteraceae, Bignoniaceae, Sapindaceae, Malpighiaceae e Apocynaceae (sendo esta a ordem de riqueza).

Por outro lado, é notável a variação de famílias de lianas em outras florestas tropicais (Tab. 2) e, embora para um mesmo continente geralmente haja uniformidade quanto às famílias mais ricas (são praticamente as mesmas), existe variação quanto à ordem de riqueza. Por exemplo, Bignoniaceae é a família com maior número de espécies no presente estudo e sempre está dentre as mais proeminentes nos neotrópicos, enquanto que Fabaceae possui posição de destaque na Ásia, além de ser comum no continente americano e estar em posição de destaque na composição das florestas ombrófilas deste continente. A importância de Bignoniaceae como a família com maior número de espécies de lianas já havia sido ressaltada anteriormente para outras florestas neotropicais e, em especial, para outras florestas estacionais semideciduais do sudeste do Brasil (e.g., Morellato \& Leitão Filho 1998; Udulutsch et al. 2004; Tibiriçá et al. 2006).

Dentre os gêneros mais ricos em número de espécies, destacam-se Arrabidaea e Serjania, os quais além de pertenceram às famílias com maior riqueza específica (Bignoniaceae e Sapindaceae, respectivamente), também figuram entre os mais ricos em outros levantamentos florísticos realizados no mesmo tipo de formação florestal (e.g., Morelatto \& Leitão Filho 1998; Tibiriçá et al. 2006).

Considerando o número de gêneros e o número de espécies por gênero, Bignoniaceae figura como a família mais rica, o que também foi evidenciado em outros levantamentos florísticos de lianas para a região sudeste do Brasil (e.g., Hora
\& Soares 2002; Udulutsch et al. 2004). Segundo Gentry (1991), os fatores que podem estar relacionados com os altos valores encontrados, tanto em relação ao número de espécies quanto ao de gêneros para a família, são a localização do seu centro de diversidade (o Brasil concentra o maior número de espécies) e o número de gêneros com espécies lianescentes que a família apresenta (é a família com o terceiro maior número de gêneros de trepadeiras (53) no Novo Mundo).

Um dos fatores que está diretamente ligado à riqueza de espécies e abundância de lianas é a intensidade luminosa capaz de penetrar em uma floresta, que, por sua vez, está relacionada à arquitetura da copa das árvores (Lee \& Richards 1991) e também ao histórico de perturbações desse ambiente (Morellato \& Leitão Filho 1998). Muitas lianas são dependentes da luz e desenvolvem-se bem tanto em clareiras (Putz 1984) quanto nas bordas de fragmentos, o que justifica o aumento da densidade dessa forma de vida em áreas degradadas (Putz 1984; Pérez-Salicrup et al. 2001a; Schnitzer \& Carson 2001). Nesse contexto, é possível justificar as diferenças encontradas na composição florística da borda e das parcelas do fragmento florestal estudado e também a ocorrência exclusiva de algumas espécies em bordas e clareiras.

Quanto às diferenças biomecânicas encontradas nas diversas famílias de lianas, poucos foram os estudos que buscaram classificar e quantificar os mecanismos de ascensão (e.g., Putz 1984; Lima et al. 1997; Durigon et al. 2009). O grande número de espécies com estruturas preênseis $(57 \%$ do total amostrado) e o reduzido número de famílias onde elas ocorrem, considerando a área de estudo, reforçam as indicações propostas por Gentry (1991), de que em regiões neotropicais os grupos com maior sucesso adaptativo foram aqueles que desenvolveram mecanismos de ascensão especializados (e.g., gavinhas), o que ocorreu em poucas famílias.

Embora a forma volúvel seja considerada "menos especializada" que a forma preênsil (Darwin 1865; Teramura et al. 1991), no presente estudo as lianas volúveis tiveram alta representatividade (29\%), o que é indicativo de sua importância na radiação do hábito lianescente entre as famílias de plantas vasculares, como também foi observado por Lima et al. (1997).

Com o aumento recente de estudos direcionados às lianas, é possível afirmar que para as florestas estacionais semideciduais do sudeste brasileiro existe um padrão quanto às famílias com maior riqueza específica e também quanto à forma de ascensão para 
as espécies de trepadeiras lenhosas. Nessas florestas, as famílias de lianas apontadas como as mais ricas são Bignoniaceae, Sapindaceae e Malpighiaceae (e.g., Morellato \& Leitão Filho 1998; Udulutsch et al. 2004; Rezende et al. 2007) e a forma de ascensão apresentada pela maioria das espécies é a forma preênsil (Udulutsch et al. 2004; Tibiriçá et al. 2006; Rezende et al. 2007).

Além disso, o conjunto de informações disponíveis até o momento confere às lianas um papel de destaque na dinâmica das comunidades florestais, contribuindo tanto com a diversidade biológica como também participando de uma série de processos e/ou funções vitais à manutenção da estrutura florestal. Dentre esses processos, destacam-se: 1) o fornecimento de alimento para polinizadores e dispersores em épocas que as demais formas de vida não oferecem recursos (Gentry 1991; Ødegaard 2000); 2) o auxílio no deslocamento de animais arborícolas através da conexão das copas das árvores (Emmons \& Gentry 1983); 3) previnem a erosão no solo, assim como as demais formas de vida (Putz 1983; Muthuramkumar \& Parthasarathy 2000); 4) desempenham papel fundamental em alguns processos ecológicos diretamente ligados ao equilíbrio do ecossistema, tais como transpiração total e sequestro de carbono (Schnitzer \& Bongers 2002); e, por fim, 5) a atuação destas plantas como bio-indicadoras, com importância voltada à caracterização de ambientes (Putz 1984; Richards 1996; Schnitzer \& Bongers 2002) e até mesmo de formações vegetacionais, como destacado, no presente estudo, para as florestas estacionais semideciduais do sudeste brasileiro.

\section{Chaves de identificação para as famílias e espécies de lianas}

1. Plantas com folhas compostas.

2. Filotaxia oposta Bignoniaceae (Chave II)

2'. Filotaxia alterna.

3. Plantas sem gavinha Fabaceae (Chave V)

3'. Plantas com gavinha.

4. Folhas bifolioladas Fabaceae (Chave V)

4'. Folhas com 3 ou mais folíolos Sapindaceae (Chave VIII)

1'. Plantas com folhas simples.

5. Filotaxia oposta.

6. Plantas com látex Apocynaceae (Chave I)

6. Plantas sem látex.

7. Caule armado Nyctaginaceae (Chave VII)

7'. Caule inerme.

8. Presença de nectários extraflorais no limbo foliar ou pecíolo; tricomas malpiguiáceos (em forma de "T") presentes Malpighiaceae (Chave VI)

8'. Nectários extraflorais e tricomas malpiguiáceos ausentes.

9. Folhas com margem serrilhada.

10. Folhas com venação broquidódroma; caule com a formação de ganchos Celastraceae (Chave III)

10'. Folhas com venação semicraspedódroma; caule sem ganchos Verbenaceae (73. Petrea volubilis)

9'. Folhas com margem inteira.

11. Folhas com face abaxial canescente .... Trigoniaceae (71. Trigonia nivea)

11'. Folhas com face abaxial puberulenta a tomentosa, nunca canescente.

12. Folhas ovadas a elípticas, ápice agudo a arredondado, indumento amarelo a ferrugíneo, face adaxial com as nervuras principal e secundárias evidentes .... Acanthaceae (1. Mendoncia velloziana)

12'. Folhas lanceoladas, ápice acuminado, indumento alvo, face adaxial apenas com a nervura principal evidente Amaranthaceae (2. Hebanthe paniculata)

5'. Filotaxia alterna

13. Caule armado. 
14. Folhas com domácias Ulmaceae (72. Celtis iguanae)

14'. Folhas sem domácias.

15. Folhas carnosas, com apenas a nervura central evidente ... Cactaceae (35. Pereskia aculeata)

15'. Folhas papiráceas ou cartáceas, com nervuras principal e secundárias evidentes.

16. Nós com 1 espinho Nyctaginaceae (Chave VII)

16'. Nós com 2 espinhos Phytolaccaceae (56. Seguiera americana)

13'. Caule inerme.

17. Plantas com gavinhas.

18. Gavinhas na axila das folhas

Rhamnaceae (57. Gouania acalyphoides)

18'. Gavinhas opostas às folhas Vitaceae (74. Cissus verticillata)

17'. Plantas sem gavinhas.

19. Face abaxial das folhas com tricomas simples Dilleniaceae (Chave IV)

19'. Face abaxial das folhas com tricomas estrelados ou dendríticos

20. Folhas com venação broquidódroma Solanaceae (Chave IX)

20'. Folhas com venação campilódroma Malvaceae (53. Byttneria catalpifolia)

\section{Chave I: Apocynaceae}

1. Plantas com filotaxia verticilada

3. Condylocarpon isthmicum

1. Plantas com filotaxia oposta.

2. Domácias na superfície abaxial das folhas.

3. Domácias urceoladas

4. Forsteronia australis

3'. Domácias membranoso-pilosas ou apenas pilosas.

4. Folhas lanceoladas a oblongas, base cordada 5. Forsteronia pilosa

4'. Folhas ovadas, base obtusa a arredondada 6. Forsteronia pubescens

2'. Superfície abaxial das folhas sem domácias.

5. Plantas com látex incolor ....

9. Temnadenia violacea

5'. Plantas com látex branco.

6. Plantas com caule e folhas glabros; folhas ovadas a elípticas

7. Prestonia coalita

6'. Plantas com caule e folhas tomentosos; folhas orbiculares

8. Prestonia tomentosa

\section{Chave II: Bignoniaceae}

1. Plantas com gavinhas simples.

2. Gavinhas com ápice modificado em disco adesivo 26. Glaziovia bauhinioides

2'. Gavinhas com ápice simples, não modificado em disco adesivo.

3. Folíolos com face abaxial desprovida de domácias.

4. Caule anguloso, tetragonal em seção transversal

22. Clytostoma sciuripabulum

4'. Caule cilíndrico, circular em seção transversal.

5. Folíolos com face abaxial lepidota.

6. Folíolos com margem cartilaginosa e alva; região interpeciolar sem campo .... 11. Adenocalymma marginatum

6'. Folíolos com margem não cartilaginosa e da mesma coloração do limbo; região interpeciolar com campo glandular.

7. Face abaxial dos folíolos esparsamente lepidota, com escamas douradas concentradas na região basal; pecíolo com mais de $3,5 \mathrm{~cm}$ de compr.; folíolos verdes a oliváceos quando secos ..... 16. Arrabidaea conjugata

7'. Face abaxial dos folíolos densamente lepidota, com escamas alvoamareladas; pecíolo com até $2 \mathrm{~cm}$ de compr.; folíolos castanhos a enegrecidos quando secos

5'. Folíolos com face abaxial não lepidota. 17. Arrabidae a florida

8. Folíolos vermelhos quando secos; pseudoestípulas caducas, membranáceas, sem nectários 15. Arrabidaea chica

8'. Folíolos verde-oliváceos a castanhos quando secos; pseudoestípulas persistentes, lenhosas, com nectários pateliformes. 
9. Pseudoestípulas simétricas, não falcadas; folíolos com face adaxial lustrosa.

9'. Pseudoestípulas assimétricas, falcadas; folíolos com face adaxial opaca 10. Adenocalymma bracteatum

12. Adenocalymma paulistarum

3'. Folíolos com domácias na face abaxial.

10. Caule e folhas viscosos devido à presença de tricomas glandulares, principalmente nas porções jovens 19. Arrabidaea pulchra

10'. Caule e folhas não viscosos, sem tricomas glandulares.

11. Caule fistuloso 33. Stizophyllum perforatum

11'. Caule não fistuloso.

12. Folíolos com face abaxial lepidota.

13. Folíolos com tricomas, se presentes, apenas nas domácias.

14. Domácias com superfície glabra e região de abertura com poucos tricomas esparsos a glabrescente 21. Arrabidaea triplinervia

14'. Domácias com superfície e região de abertura tomentosas .

25. Fridericia speciosa

13'. Folíolos puberulentos a tomentosos.

15. Folíolos sem campo glandular na região basal da face abaxial e base simétrica 20. Arrabidaea samydoides

15'. Folíolos com campo glandular na região basal da face abaxial e base assimétrica

27. Lundia obliqua

12'. Folíolos com face abaxial não lepidota.

16. Face abaxial dos folíolos com domácias membranoso-pilosas entre as nervuras principal e secundárias e domácias lineares e pilosas ao longo da nervura principal.

17. Face adaxial dos folíolos com tricomas concentrados apenas ao longo das nervuras e na margem; folíolos com ápice agudo ... 18. Arrabidaea pulchella

17'. Face adaxial dos folíolos inteiramente pubérula; folíolos com ápice acuminado 23. Cuspidaria convoluta

16'. Face abaxial dos folíolos com domácias membranosas apenas entre as nervuras principal e secundárias.

18. Folíolos com face abaxial e superfície das domácias glabras

21. Arrabidaea triplinervia

18'. Folíolos com face abaxial e superfície das domácias pubérulas a tomentulosas

27. Lundia obliqua

1. Plantas com gavinhas ramificadas.

19. Gavinhas trífidas, bi-ramificadas.

20. Porções apicais da gavinha simples, não modificadas em disco adesivo; pseudo-estípulas foliáceas 31. Pithecoctenium crucigerum

20'. Porções apicais da gavinha modificadas em disco adesivo; pseudoestípulas inconspícuas, reduzidas 34. Tynanthus micranthus

19’. Gavinhas trífidas, uni-ramificadas.

21. Porções terminais das gavinhas uncinadas ou modificadas em disco adesivo.

22. Gavinhas uncinadas.

23. Folíolos com face abaxial puberulenta a pubérula; pseudoestípulas membranáceas e lanceoladas a lineares 28. Macfadyena mollis

23'. Folíolos com face abaxial glabra; pseudoestípulas lenhosas e ovadas

22'. Gavinhas com discos adesivos.

29. Macfadyena unguis-cati

24. Pseudoestípulas foliáceas

26. Glaziovia bauhinioides

24'. Pseudoestípulas inconspícuas, reduzidas 34. Tynanthus micranthus

21'. Porções terminais das gavinhas simples, sem modificações.

25. Pseudoestípulas foliáceas 14. Anemopaegma chamberlaynii

25'. Pseudoestípulas inconspícuas, pouco desenvolvidas, nunca foliáceas. 
26. Base dos folíolos com campo nectarífero na face abaxial.

27. Folíolos com venação acródroma supra-basal; face abaxial com escamas alvas e opacas, inconspícuas a olho nu 30. Mansoa difficilis

27'. Folíolos com venação broquidódroma; face abaxial com escamas amarelas e lustrosas, visíveis a olho nu

32. Pyrostegia venusta

26'. Base dos folíolos sem campo nectarífero.

28. Folíolos com face abaxial apenas lepidota, sem tricomas; caule 6-costulado, anguloso

13. Amphilophium paniculatum

28'. Folíolos com face abaxial tomentosa e lepidota; caule liso e cilíndrico

24. Distictella elongata

\section{Chave III: Celastraceae}

1. Folhas membranáceas, lanceoladas a oblongas, face adaxial lustrosa 36. Anthodon decussatum

1'. Folhas cartáceas, elípticas a obovadas, face adaxial opaca 37. Hippocratea volubilis

\section{Chave IV: Dilleniaceae}

1. Folhas com a face adaxial rugosa, áspera ao toque

38. Davilla rugosa

1'. Folhas com a face adaxial lisa ao toque 39. Doliocarpus dentatus

\section{Chave V: Fabaceae}

1. Planta com folhas bipinadas.

2. Pecíolo e raque foliar com nectários cupuliformes, não pedunculados 42. Acacia polyphylla

2'. Pecíolo e raque foliar com nectários pedunculados.

3. Foliólulos sem tufo de tricomas na base; tricomas apenas na margem ..... 40. Acacia molissima

3'. Foliólulos com tufo de tricomas na base, ao lado da nervura principal ...... 41. Acacia plumosa

1'. Plantas com folhas bifolioladas, trifolioladas ou pinadas.

4. Planta com folhas bifolioladas, folíolos fundidos; presença de gavinha axilar 43. Bauhinia microstachya

4'. Planta com folhas trifolioladas ou pinadas, folíolos não fundidos; gavinha ausente.

5. Folhas com mais de 5 folíolos 44. Dalbergia frutescens

5'. Folhas trifolioladas 45. Dioclea cf. virgata

\section{Chave VI: Malpighiaceae}

1. Nectários extraflorais na margem das folhas

51. Tetrapterys multigladulosa

1. Nectários extraflorais no pecíolo ou no limbo foliar, mas nunca na margem.

2. Nectários extraflorais no limbo foliar.

3. Nectários na região basal da face abaxial, próximos à nervura central; folhas planas e face adaxial castanho-enegrecida quando seca 46. Banisteriopsis muricata

3'. Nectários na região mediana da face abaxial, entre a margem e a nervura principal; folhas buladas e face adaxial verde a olivácea quando seca 50. Mascagnia cordifolia

2'. Nectários extraflorais no pecíolo.

4. Nectários na base dos pecíolos, na conexão com o caule 49. Heteropterys sp.

4'. Nectários na porção mediana dos pecíolos ou no ápice.

5. Nectários no ápice dos pecíolos, próximos à base da folha .... 52. Tetrapterys phlomoides 5'. Nectários na porção mediana dos pecíolos.

6. Nectários tanto no pecíolo quanto na base das folhas; folhas, quando secas, com face adaxial castanha a enegrecida e opaca 46. Banisteriopsis muricata

6'. Nectários apenas no pecíolo; folhas, quando secas, com face adaxial castanho enegrecida e lustrosa ou verde-olivácea e opaca.

7. Folhas orbiculares a ovadas, face adaxial verde-olivácea e opaca quando seca e abaxial canescente 47. Banisteriopsis oxyclada 
7'. Folhas lanceoladas a oblongas, face adaxial castanho-enegrecida e lustrosa quando seca e abaxial com poucos tricomas esparsos

48. Dicella bracteosa

\section{Chave VII: Nyctaginaceae}

1. Folhas verde-oliváceas quando secas, face abaxial tomentosa a velutina ..... 54. Bougainvillea glabra

1'. Folhas castanho-enegrecidas quando secas, face abaxial apresentando tricomas apenas na região mediana, ao longo da nervura principal e base das secundárias

55. Pisonia aculeata

\section{Chave VIII: Sapindaceae}

1. Folhas pinadas

2. Caule com um único estelo; par de folíolos basal com 3 foliólulos

59. Paullinia rhomboidea

2'. Caule com um estelo central e 8 supernumerários; folíolos basais simples

66. Serjania pinnatifolia

1'. Folhas trifolioladas ou biternadas.

3. Folhas trifolioladas.

4. Folíolos com venação acródroma supra-basal

67. Thinouia ventricosa

4'. Folíolos com venação craspedódroma

68. Urvillea laevis

3'. Folhas biternadas.

5. Caule com um único estelo.

6. Foliólulos com face abaxial tomentosa e sem domácias

58. Cardiospermum grandiflorum

6'. Foliólulos com tricomas apenas na margem e sobre as nervuras e domácias da face abaxial 64. Serjania meridionalis

5. Caule com um estelo central e estelos supernumerários.

7. Caule com estelo central do mesmo tamanho dos demais 61. Serjania fuscifolia

7'. Caule com estelo central maior que os supernumerários.

8. Face abaxial dos foliólulos sem domácias; 9 estelos supernumerários

65. Serjania multiflora

8'. Face abaxial dos foliólulos com domácias; 5-7 estelos supernumerários.

9. Caule com estelos supernumerários agrupados 2-2-1, de forma equidistante

9'. Caule com estelos supernumerários não equidistantes.

62. Serjania glabrata

10. Estípula triangular persistente

60. Serjania caracasana

10'. Estípula linear caduca, deixando cicatriz semi-lunar

63. Serjania laruotteana

\section{Chave IX: Solanaceae}

1. Folhas ovadas, face adaxial glabra ou com tricomas apenas sobre a nervura principal e abaxial com tricomas estrelados, com 3 ou 4 ramificações 69. Lycianthes australe

1'. Folhas lanceoladas, face abaxial e adaxial com tricomas estrelados, sempre com mais de 5 ramificações

70. Solanum hirtellum

\section{Agradecimentos}

Agradecemos aos taxonomistas Julio A. Lombardi, Luiza S. Kinoshita, Marco A. Assis, Maria Cândida H. Mamede, María Silvia Ferrucci e João Renato Stehmann o auxílio nas identificações e ao Haroldo C. de Lima e a um revisor anônimo as valiosas sugestões. Também agradecemos à FAPESP as bolsas e auxílio à pesquisa concedidos
(RGU proc. 01/11558-5, RRR proc. 99/09635-0 e PD proc. 02/09762-6).

\section{Referências}

APG III. 2009. An update of the Angiosperm Phylogeny Group classification for the orders and families of flowering plants: APG III. Botanical Journal of the Linnean Society 161: 105-121. 
Balée, W. \& Campbell, D.G. 1990. Evidence for the successional status of liana forest (Xingu river basin, amazonian Brazil). Biotropica 22: 36-47.

Barros, A.A.M.; Ribas, L.A. \& Araujo, D.S.D. 2009. Trepadeiras do Parque Estadual da Serra da Tiririca (Rio de Janeiro, Brasil). Rodriguésia 60: 681-694.

Burns, K.C. \& Dawson, J. 2005. Patterns in the diversity and distribution of epiphytes and vines in a New Zealand forest. Austral Ecology 30: 883-891.

Clark, D.B. \& Clark, D.A. 1990. Distribution and effects on tree growth of lianas and woody hemiepiphytes in a Costa Rican tropical wet forest. Journal of Tropical Ecology 6: 321-331.

Darwin, C. 1865. On the movements and habits of climbing plants. Journal of the Linnean Society. Botany. 9: 1-118.

Durigon, J.; Canto-Dorow, T.S. \& Eisinger, S.M. 2009. Composição florística de trepadeiras ocorrentes em bordas de fragmentos de floresta estacional, Santa Maria, Rio Grande do Sul, Brasil. Rodriguésia 60: 415-422.

Eilu, G. 2000. Liana abundance in three tropical rain forests of western Uganda. Selbyana 21: 30-37.

Emmons, L.H. \& Gentry, A.H. 1983. Tropical structure and the distribution of gliding and prehensile vertebrates. The American Naturalist 121: 513-524.

Feroz, S.M.; Hagihara, A. \& Yokota, M. 2006. Stand structure and woody species diversity in relation to stand stratification in a subtropical evergreen broadleaf forest, Okinawa Island. Journal of Plant Research 119: 293-301.

Gentry, A.H. 1991. The distribution and evolution of climbing plants. In: Putz, F.E. \& Mooney, H.A. The biology of vines. Cambridge University Press, Cambridge. Pp. 3-49.

Gentry, A.H. 1996. A field guide to the families and genera of woody plants of Northwest South America (Colombia, Ecuador, Peru) with supplementary notes on herbaceous taxa. 2ed. The University of Chicago Press, Chicago and London. 920p.

Gentry, A.H. \& Dodson, C.H. 1987a. Contribution of nontrees to species richness of a tropical rain forest. Biotropica 19: 149-156.

Gentry, A.H. \& Dodson, C.H. 1987b. Diversity and biogeography of neotropical vascular epiphytes. Annals of the Missouri Botanical Garden 74: 205-233.

Hegarty, E.E. 1991. Vine-host interactions. In: Putz, F.E. \& Mooney, H.A. The biology of vines. Cambridge University Press, Cambridge. Pp. 357-375.

Hegarty, E.E. \& Caballé, G. 1991. Distribution and abundance of vines in forest communities. In: Putz, F.E. \& Mooney, H.A. The biology of vines. Cambridge University Press, Cambridge. Pp. 313-335.

Hora, R.C. \& Soares, J.J. 2002. Estrutura fitossociológica da comunidade de lianas em uma floresta estacional semidecidual na Fazenda Canchim, São Carlos, SP. Revista Brasileira de Botânica 25: 323-329.
Ibarra-Manríquez, G. \& Martínez-Ramos, M. 2002. Landscape variation of liana comunities in a neotropical rain forest. Plant Ecology 160: 91-112.

Isnard, S. \& Silk, W.K. 2009. Moving with climbing plants from Charles Darwin's time into the 21st century. American Journal of Botany 96: 1205-1221.

Köppen, W.P. 1948. Climatologia. Fundo de Cultura Econômica. Cidade do México, Buenos Aires. 479p.

Krings, A. 2000. Floristic and ecology of mesoamerican montane climber communities: Monteverde, Costa Rica. Selbyana 21: 156-164.

Lee, D.W. \& Richards, J.H. 1991. Heteroblastic development in vines. In: Putz, F.E. \& Mooney, H.A. The biology of vines. Cambridge University Press, Cambridge. Pp. 205-243.

Leitão Filho, H.F. 1995. A vegetação da reserva de Santa Genebra. In: Morellato, L.P.C. \& Leitão Filho, H.F. Ecologia e preservação de uma floresta tropical urbana, Reserva de Santa Genebra. Ed. UNICAMP, Campinas. Pp. 19-29.

Lima, H.C.; Lima, M.P.M.; Vaz, A.M.S. \& Pessoa, S.V.A. 1997. Trepadeiras da reserva ecológica de Macaé de Cima. In: Guedes-Brunini, R.R. \& Lima, H.C. Serra de Macaé de Cima: diversidade florística e conservação em Mata Atlântica. Jardim Botânico do Rio de Janeiro, Rio de Janeiro. Pp. 75-87.

Lowe, R.G. \& Walker, P. 1977. Classification of canopy, stem, crown status and climber infestation in a natural tropical forest in Nigeria. Journal of Applied Ecology 14: 897-903.

Mattos, I.F.A.; Rossi, M.; Silva, D.A. \& Pfeiffer, R.M. 1996. Levantamento do meio biofísico e avaliação da fragilidade do ecossistema na Estação Ecológica dos Caetetus, SP. Sociedade e Natureza 15: 388-393.

Menninger, E.A. 1970. Flowering vines of the world: an encyclopedia of climbing plants. Hearthside Press Incorporated, New York. 410p.

Morellato, L.P.C. \& Leitão Filho, H.F. 1998. Levantamento florístico da comunidade de trepadeiras de uma floresta semidecídua no sudeste do Brasil. Boletim do Museu Nacional do Rio de Janeiro, Botânica 103: $1-15$.

Muoghalu, J.I. \& Okeesan, O.O. 2005. Climber species composition, abundance and relationship with trees in a Nigerian secondary forest. African Journal of Ecology 43: 258-266.

Muthuramkumar, S. \& Parthasarathy, N. 2000. Alpha diversity of lianas in a tropical evergreen forest in the Anamalais, Western Ghats, India. Diversity and Distributions 6: 1-14.

Ødegaard, F. 2000. The relative importance of trees versus lianas as hosts for phytophagous beetles (Coleoptera) in tropical forests. Journal of Biogeography 27: 283-296.

Oliveira, A.N.; Amaral, I.L.; Ramos, M.B.P. \& Formiga, K.M. 2008. Aspectos florísticos e ecológicos de 
grandes lianas em três ambientes florestais de terra firme na Amazônia Central. Acta Amazonica 38: 421-430.

Pérez-Salicrup, D.R.; Claros, A.; Guzman, R.; Licona, J.C.; Ledezma, F.; Pinard, M.A. \& Putz, F.E. 2001a. Cost and efficiency of cutting lianas in a lowland Liana Forest of Bolivia. Biotropica 33: 324-329.

Pérez-Salicrup, D.R.; Sork, V.L. \& Putz, F.E. 2001 b. Lianas and trees in a liana forest of Amazonian Bolivia. Biotropica 33: 34-47.

Putz, F.E. 1983. Liana biomass and leaf area of terra firme forest in the Rio Negro basin, Venezuela. Biotropica 15: 185-189.

Putz, F.E. 1984. The natural history of lianas on Barro Colorado Island, Panama. Ecology 65: 1713-1724.

Putz, F.E. \& Chai, P. 1987. Ecological studies of lianas in Lambir National Park, Sarawak. Journal of Ecology 75: 523-531.

Putz, F.E. \& Mooney, H.A. 1991. The biology of vines. Cambridge University Press, Cambridge. 526p.

Putz, F.E. \& Windsor, D.M. 1987. Liana phenology on Barro Colorado Island, Panama. Biotropica 19: 334-341.

Rezende, A.A. \& Ranga, N.T. 2005. Lianas da estação ecológica do Noroeste Paulista, São José do Rio Preto/Mirassol, SP, Brasil. Acta Botanica Brasilica 19: 273-279.

Rezende, A.A.; Ranga, N.T. \& Pereira, R.A.S. 2007. Lianas de uma floresta estacional semidecidual, município de Paulo de Faria, norte do estado de São Paulo, Brasil. Revista Brasileira de Botânica 30: 451-461.

Richards, P.W. 1952. The tropical rain forest. Cambridge University Press, Cambridge. 450p.

Richards, P.W. 1996. The tropical rain forest: an ecological study. Cambridge University Press, Cambridge. 600p.

Schnitzer, S.A. \& Bongers, F. 2002. The ecology of lianas and their role in forests. Trends in Ecology and Evolution 17: 223-230.

Schnitzer, S.A. \& Carson, W.P. 2001. Treefall gaps and the maintenance of species diversity in a tropical forest. Ecology 82: 913-919.

Silva, A.F. \& Leitão Filho, H.F. 1982. Composição florística e estrutura de um trecho de mata atlântica de encosta no município de Ubatuba (São Paulo, Brasil). Revista Brasileira de Botânica 5: 43-52.

Steege, H.T.; Sabatier, D.; Castellanos, H.; Andel, T.; Duivenvoorden, J.; Oliveira, A.A.; Ek, R.; Lilwah, R.; Maas, P. \& Mori, S. 2000. An analysis of the floristic composition and diversity of Amazonian
Forests including those of the Guiana Shield. Journal of Tropical Ecology 16: 801-828.

Steentoft, M. 1988. Flowering plants in west Africa. Cambridge University Press, Cambridge. 364p.

Summerbell, G. 1991. Regeneration of complex notophyll vine forest (humid subtropical rainforest) in eastern Australia - a review. Cunninghamia: ecological contributions from the National Herbarium of New South Wales 2: 391-410.

Tabarelli, M. \& Mantovani, W. 1999. A riqueza de espécies arbóreas na floresta atlântica de encosta no Estado de São Paulo (Brasil). Revista Brasileira de Botânica 22: 217-223.

Teramura, A.H.; Gold, W.G. \& Forseth, I.N. 1991. Physiological ecology of mesic, temperate woody vines. In: Putz, F.E. \& Mooney, H.A. The biology of vines. Cambridge University Press, Cambridge. Pp. 245-285.

Tibiriçá, Y.J.A.; Coelho, L.F.M. \& Moura, L. C. 2006. Florística de lianas em um fragmento de floresta estacional semidecidual, Parque Estadual de Vassununga, Santa Rita do Passa Quatro, SP, Brasil. Acta Botanica Brasilica 20: 339-346.

Udulutsch, R.G. 2004. Composição florística da comunidade de lianas lenhosas em duas formações florestais do estado de São Paulo. Dissertação de Mestrado. Universidade de São Paulo, Piracicaba. 114p.

Udulutsch, R.G.; Assis, M.A. \& Picchi, D.G. 2004. Florística de trepadeiras numa floresta estacional semidecídua, Rio Claro - Araras, estado de São Paulo, Brasil. Revista Brasileira de Botânica 27: 125-134.

Vaz, A.M.S. \& Vieira, C.M. 1994. Identificação de famílias com espécies trepadeiras. In: GuedesBrunini, R.R. \& Lima, H.C. Serra de Macaé de Cima: diversidade florística e conservação em Mata Atlântica. Jardim Botânico do Rio de Janeiro, Rio de Janeiro, 75-82.

Veloso, H.P. 1991. Sistema fitogeográfico. In: Fundação Instituto Brasileiro de Geografia e Estatística. Manual técnico da vegetação brasileira. IBGE, Rio de Janeiro. Pp. 9-38.

Veloso, H.P. \& Góes-Filho, L. 1982. Fitogeografia brasileira: classificação fisionômico- ecológica da vegetação neotropical. In: Ministério das Minas e Energia. Boletim Técnico do Projeto RADAMBRASIL, Série Vegetação. IBGE, Salvador. Pp. 1-86.

Zhu, H. 2008. Species composition and diversity of lianas in tropical forests of southern Yunnan (Xishuangbanna), south-western China. Journal of Tropical Forest Science 20: 111-122. 